Dermatology 2010;221:320

DOI: $10.1159 / 000318005$

\section{Concurrent Sarcoidosis and Melanoma: Coexistence More than by Chance?}

Foteini Malli, Konstantinos I. Gourgoulianis, Zoe Daniil

Respiratory Medicine Department, University of Thessaly School of Medicine, University Hospital of Larissa, Larissa, Greece

Key Words

Melanoma $\cdot$ Sarcoidosis $\cdot$ Tumor necrosis factor

In a very interesting paper published recently in this journal, Seve et al. [1] reported a prevalence of $0.58 \%$ of sarcoidosis in a cohort of 1,199 patients with melanoma. The authors reviewed the literature and additionally identified 13 patients with sarcoidosis associated with melanoma.

In our respiratory medicine department, we identified 2 cases of melanoma among 85 sarcoidosis patients that we consecutively diagnosed at our institution. The first patient is a 37 -year-old man, who presented with dry cough, fever, fatigue and parenchymal infiltrates bilaterally. He was subjected to transbronchial biopsy that revealed the presence of noncaseating granulomas. The patient received corticosteroid therapy for 30 months. Fifteen months after the discontinuation of corticosteroids he was diagnosed as having nodular malignant melanoma of the left ear (Clark level V and Breslow depth of $4 \mathrm{~mm}$ ) that was surgically excised with disease-free borders. Five months after the diagnosis of melanoma he presented a relapse of sarcoidosis with progressive symptomatic pulmonary disease and he is currently receiving corticosteroid therapy with signs of improvement. His follow-up until today (22 months after the melanoma diagnosis) has not revealed any signs of metastatic disease.

The second patient is a 51-year-old woman who presented with progressive dyspnea, mediastinal lymphadenopathy and small nodules involving the right middle lobe. There were no palpable peripheral lymph nodes on physical examination and abdominal computed tomography did not reveal the presence of enlarged lymph nodes. One year prior she had been diagnosed as having ulcerated malignant melanoma (Clark level IV and Breslow depth of $3 \mathrm{~mm}$ ) of the right leg which had been surgically excised without any additional therapy required. The patient underwent mediastinoscopy and the histology of the resected lymph nodes confirmed the diagnosis of sarcoidosis (noncaseating granulomas) while excluding the presence of malignancy. It should be noted that in the past the patient had not received any treatment that has been associated with the development of sarcoidosis or sarcoid reaction, e.g. interferon- $\alpha$ therapy.

Although our group of patients is of limited number, we believe that the data presented provide supporting evidence to those of Seve et al. [1] concerning the association of sarcoidosis with melanoma. Increased risk of melanoma among sarcoidosis patients has been reported by earlier studies [2]. However, in our referral center, the incidence of melanoma in patients with sarcoidosis seems to be higher than expected according to previous studies. One possible explanation is the intense exposure to sunlight in our geographic region (Greece) since exposure to ultraviolet light is one of the major risk factors for the development of melanoma.

However, one could hypothesize that a common pathogenetic link between the 2 disease entities exists. Mounting evidence in the literature suggests that tumor necrosis factor- $\alpha$ (TNF- $\alpha$ ) plays a crucial role in the pathogenetic cascade of sarcoidosis; the data suggest that TNF- $\alpha$ regulates granuloma formation and persistence, while TNF- $\alpha$ concentrations are associated with disease activity and prognosis $[3,4]$. Additionally, studies have demonstrated an association between TNF- $\alpha$ gene polymorphisms and the development of sarcoidosis [5]. Interestingly, researchers have reported a positive association of TNF- $\alpha$ gene polymorphisms and melanoma that may influence disease susceptibility [6]. The data suggest that TNF- $\alpha$, which is upregulated by ultraviolet exposure, may contribute to tumor escape from the immune response [7]. Although the aforementioned observations cannot substantiate the latter hypothesis, they provide a novel explanation of the clinical overlap of the 2 diseases which, in our opinion, merits further investigations.

In conclusion, patients with sarcoidosis appear to be at significantly increased risk of melanoma, particularly in countries with intense sunlight. Therefore, despite their often favorable prognosis these patients require increased medical attention.

\section{References}

1 Seve P, Schott AM, Pavic M, Broussolle C, Gilis L, Thomas L: Sarcoidosis and melanoma: a referral center study of 1,199 cases. Dermatology 2009;219:25-31.

2 Cohen PR, Kurzrock R: Sarcoidosis and malignancy. Clin Dermatol 2007;25:326-333.

3 Baughman RP, Lower EE, du Bois RM: Sarcoidosis. Lancet 2003;361: 1111-1118.

4 Ziegenhagen MW, Benner UK, Zissel G, Zabel P, Schlaak M, MullerQuernheim J: Sarcoidosis: TNF- $\alpha$ release from alveolar macrophages and serum level of sIL-2R are prognostic markers. Am J Respir Crit Care Med 1997;156:1586-1592.

5 Sharma S, Ghosh B, Sharma SK: Association of TNF polymorphisms with sarcoidosis, its prognosis and tumour necrosis factor (TNF)- $\alpha$ levels in Asian Indians. Clin Exp Immunol 2008;151:251-259.

6 Nikolova PN, Pawelec GP, Mihailova SM, Ivanova MI, Myhailova AP, Baltadjieva DN, Marinova DI, Ivanova SS, Naumova EJ: Association of cytokine gene polymorphisms with malignant melanoma in Caucasian population. Cancer Immunol Immunother 2007;56:371-379.

7 Bazzoni F, Kruys V, Shakhov A, Jongeneel CV, Beutler B: Analysis of tumor necrosis factor promoter responses to ultraviolet light. J Clin Invest 1994;93:56-62.

\section{KARGER}

(C) 2010 S. Karger AG, Basel

Fax +41613061234

E-Mail karger@karger.ch

www.karger.com
Accessible online at:

www.karger.com/drm
Assist. Prof. Zoe Daniil

University Hospital of Larissa

Respiratory Medicine Department, Mezourlo (Biopolis)

GR-41110 Larissa (Greece)

Tel. +30 241350 2898, Fax +30 241350 1563, E-Mail zdaniil @ med.uth.gr 